\title{
Retraction Note to: Kuhn-Grün analysis of polarized Rayleigh and Raman scattering experiments to deduce segmental orientation in polymeric systems
}

\author{
Springer Production
}

Published online: 21 September 2011

(C) Springer-Verlag 2011

\section{Retraction to: Rheol Acta (2011) 50:179-198}

DOI 10.1007/s00397-011-537-2

This paper has been retracted due to multiple ethical misconduct including unauthorized naming of the coauthors by the corresponding author of the original article David Mead. Furthermore the given affiliation "Center for the Molecular Study of Condensed Soft Matter, Illinois Institute of Technology, Chicago, IL 60616, USA" was illegitimately stated by David Mead. 